American J. of Engineering and Applied Sciences 3 (2): 380-389, 2010

ISSN 1941-7020

(C) 2010 Science Publications

\title{
The Characteristics of Architecture Style of the Traditional Houses in the Mosul City-Analytical Study
}

\author{
Mozahim Mohammed Mustafa, Daizhizhong and Yuan Hong \\ Department of Architecture Design and Theory, College of Architecture and Urban Planning, \\ Chongqing University, Chongqing, China
}

\begin{abstract}
Problem statement: Mosul city distinguishes itself in its architecture style which has earned and developed through ages. However, this style is now prone to extinction. This is due to the lack of studies which clarify the characteristics of architecture style in the traditional architecture of the city and benefit from it for future designs and to maintain the architecture identity of the city. The above problem made local architects rely on Western concepts in the process of construction and expansion that occurred in this city since the second decade of the twentieth century. Approach: Therefore, there is a need to have studies showing the characteristics of architecture style of the traditional buildings in Mosul city, so that it can be invested in current and future designs. One study can not be enough to clarify the characteristics of Architecture style in the city, because of the building functional diversity, so it is necessary to focus on one type of building which are the residential houses. The residential houses represent most of the urban fabric of the Mosul city and this is a key component of the identity of the city architecture in general. Results: Thus stating the research problem as "lack of clear perception of the characteristics of architecture style of the traditional houses in Mosul city to consider in future designs" and having in mind this problem, the goal of this research has been set to clarify these characteristics. The hypothesis has been developed concerning these properties: Identification of a methodology for the research to achieve the goal and verification of the hypothesis. Conclusion: Finally, architectural style that characterized the traditional residential houses in the light of several levels, which are the basic components and formal relations (organization of space, mass configuration) and fine architectural treatments, were provided.
\end{abstract}

Key words: Architecture style, traditional architecture, architecture of Mosul in Iraq

\section{INTRODUCTION}

Mosul architecture during pre-Islamic and Islamic eras, expressed cultural interaction, the interaction with the developments of time and responsive human needs without losing the Originality. Therefore, this city had special Architecture Style, which made it a distinguished city within the Arab Islamic cities.

But over time and the multiplicity of human needs in urbanization and the social and economic development, Mosul city has experienced a huge expansion in urban area, especially in recent decades. In this period was the introduction of international architecture style, which coincided with the appearance of this development. In addition to the adoption of new architectural concepts that have emerged from the architect of that period and also rely on the methods and materials of modern construction and the process of introducing systems and engineering services in construction. All this led to the loss of the local specificity of city and losing the national heritage, although these architects try on sensitive privacy of Iraqi environmental from a climatic standpoint and inspiring heritage through symbolism.

The attempt of these architects did not lead to a positive result because of the lack of studies which show the architectural style of Mosul city, in addition to the absence of clear systematic investment of this heritage in future architecture design. Most of studies on Mosul city are characterized as historic, descriptive, investigative documentary, or non-specialist and not analytical studies devise characteristics design of the style, which can be used in the field of application in future projects (Aldeuge, 1982; Janabi, 1982; Aljumah, 1982; 1988a; 1989; 1992).

Corresponding Author: Mozahim Mohammed Mustafa, Department of Architecture Design and Theory, College of Architecture and Urban Planning, Chongqing University, Chongqing, China Tel: 008615909320101 
Based on the above and to solve the problem of loss of local privacy, it is necessary to make studies taking into consideration the characteristics of architectural style of buildings in the city of Mosul, for application in future projects. The process of defining architectural style and the characteristics statement in Mosul can not be done in one study, but in numerous studies because of the multiplicity patterns of structural, functional and richness of architecture treatments in all of these buildings.

On this basis, this research focuses on the specific pattern, which are the houses in Mosul city because the houses represents the great fabric of Mosul city and therefore it is considered the most important part in shaping the identity of the city and identify privacy of architectural style. In addition to that, this type of functional lost the privacy as the internal structure has changed dramatically from what was in the past through the advent Western culture concepts, which occurred in early of this century and led to change its features gradually and dramatically (Sangaree, 1990).

All the studies which addressed the Mosul houses were either documentary, a historical narrative or as part of a general study. Some of these studies are:

- Study of the Construction Engineering Office under supervision of Professor Thanoon (1983) and others "residential buildings in the city of Mosul", which is a documentary study of four major houses in the city of Mosul. The study includes a description of these houses in terms of design, construction terms and architectural treatments, supported by graphics and architectural shapes and illustrations (Thanoon, 1983)

- Study of Dr. Ahmad Kassem Aljumah "environmental treatments of heritage housing designs in Mosul" a study in the environmental field, as a researcher dealing with the environmental treatments such as basements that were used to siesta in the summer (Aljumah, 1988b), in addition to other studies on the housing as part of general studies about the heritage buildings in Mosul, including studies in the economic field. In the economic studies he was describing the parts of the houses and the different of these parts from one house to another according to the economic situation (Aljumah, 1988a)

- Part of Other studies have dealt with the heritage residential buildings in Mosul such as the study of Janabi (1982) which dealt in part from his study: "The internal structure of the house Mosul" by description and analysis but in general and not indepth
The above mentioned studies indicate that the previous literatures which dealt with the traditional houses in Mosul were either documentary study to some of buildings to statement of specific characteristics, or description and analysis in general without going into deep analysis. So it is difficult to take advantage from this or other studies directly to be applied in the future designs of houses in Mosul. It requires doing an analytical study that highlights the architectural characteristics of the traditional houses in Mosul to be applied by the local architect beneficiary of these and other studies to highlight the characteristics of architectural style of the traditional houses in Mosul.

Hence, we can identify the problem of finding as a" lack of clear perception the characteristics of the architecture style of the traditional houses in Mosul city to investment in future designs". Therefore, the aim of the research is to bridge this gap of scientific knowledge, since determining the characteristics of architectural style in any building is to diagnose the physical properties of architectural style of buildings in the light of multiple levels, which are the basic components and formal relations (organization of space, mass configuration) and fine architectural treatments.

The research hypothesis will state basis on the above levels, since the hypothesis involves multiple levels, so secondary hypotheses concerning these levels can be formulated as:

- Dependence on partition style and the parts dominate the total mass at the level of regulation of space and mass composition.

- The basic components per house vary with the diversity of its treatments

- The diversity and richness of arts and architectural treatments inside the Mosul house, Contrary to the outside

\section{MATERIALS AND METHODS}

Measurement of variables and sample selection: To measure the variables three basic aspects must be clarified:

- The type of measurements that are used to measure the variables

- Way to collect the information for the measurement purpose

- The selection of samples

The measurements of the variables are the qualitative measures that define the possible values. This type of measurement is in agreement with the nature of these variables. Table 1-3 depict results of the case study, showing the possible values of the variables. 
Am. J. Engg. \& Applied Sci., 3 (2): 380-389, 2010

Table 1: The results of the repeated characteristics of the basic component of Mosul houses

\begin{tabular}{|c|c|c|c|c|c|}
\hline The variables & The value in the samples & $\begin{array}{l}\text { House of } \\
\text { Algalilean }\end{array}$ & $\begin{array}{l}\text { House of } \\
\text { Abdouni }\end{array}$ & $\begin{array}{l}\text { House of } \\
\text { Altutunge }\end{array}$ & $\begin{array}{l}\text { House of } \\
\text { Ziada }\end{array}$ \\
\hline \multicolumn{6}{|l|}{ Entrances } \\
\hline \multirow[t]{2}{*}{ The main entrance } & A transitional space behind direct access & & & & $*$ \\
\hline & Entry indirectly through a transitional space refracted & * & * & $*$ & \\
\hline \multirow[t]{2}{*}{ Secondary entrances } & Direct access & & & & \\
\hline & Entry indirectly through a transitional space refracted & * & & & * \\
\hline The inner courtyard & One internal courtyard & & & & $*$ \\
\hline (the yard) & Two inner courtyard (private, general) & $*$ & $*$ & $*$ & \\
\hline \multicolumn{6}{|l|}{ The main parts } \\
\hline \multirow[t]{4}{*}{ Ewan } & The ceiling height is double volume & & & * & \\
\hline & The ceiling height is one floor or two-floor (various) & $*$ & * & & $*$ \\
\hline & Ewan ground higher than the courtyard & $*$ & $*$ & & * \\
\hline & $\begin{array}{l}\text { Ewan ground is variety (higher than courtyard } \\
\text { or the same level of the courtyard ground) }\end{array}$ & & & * & \\
\hline \multirow[t]{2}{*}{ Rooms } & Is a one space or several spaces & * & * & * & * \\
\hline & The ceiling height is one floor or two-floor (various) & $*$ & * & $*$ & $*$ \\
\hline \multirow[t]{2}{*}{ Single rooms } & Is a one space or several spaces & * & & $*$ & $*$ \\
\hline & The ceiling height is one floor or two-floor (various) & * & & * & * \\
\hline \multicolumn{6}{|l|}{ Basement } \\
\hline \multirow[t]{2}{*}{ Basement } & Under the yard only & * & & & \\
\hline & Under the yard and the structural parts & & & * & * \\
\hline *Alrhrh & Under the structural parts from one side of the house & & * & & $*$ \\
\hline \multirow[t]{2}{*}{ Galleries and cantilevers } & Overlooking the yard on one side or part of it & & * & $*$ & \\
\hline & Overlooking the yard on two side or one side and part of other & * & & & * \\
\hline \multirow[t]{2}{*}{ Kitchen } & Represents a distinct part of the house & * & * & & * \\
\hline & A space follow to the private internal courtyard & & & * & \\
\hline
\end{tabular}

*:Alrhrh is a basement which its ceiling higher than the level of courtyard ground and under the building structure

Table 2: The results of repeated characteristics of the formal relations in Mosul houses

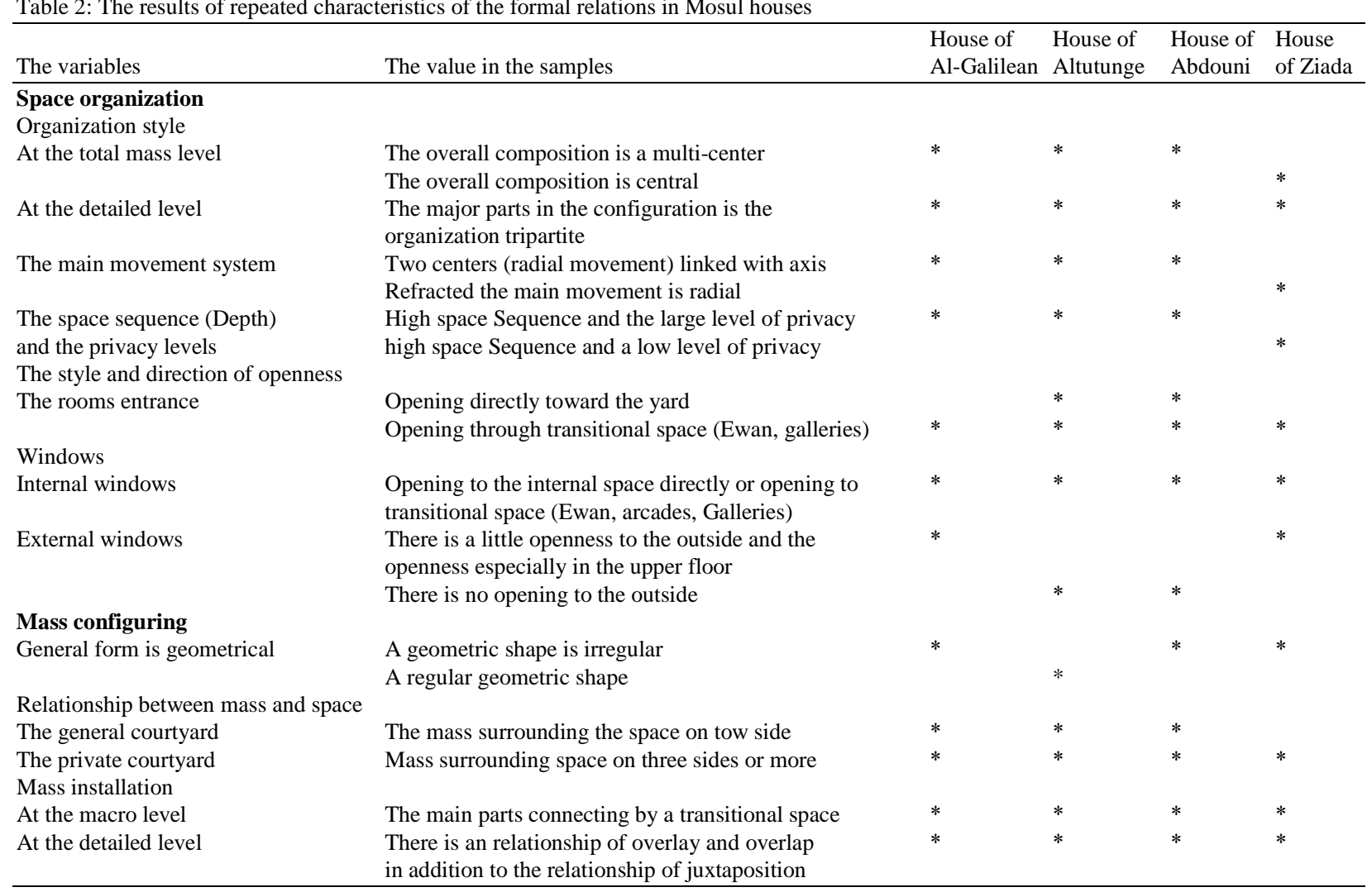


Am. J. Engg. \& Applied Sci., 3 (2): 380-389, 2010

Table 3: The results of the repeated characteristics of the architectural composition of Mosul houses

\begin{tabular}{|c|c|c|c|c|c|}
\hline The variables & The value in the samples & $\begin{array}{l}\text { House of } \\
\text { Al-Galilean }\end{array}$ & $\begin{array}{l}\text { House of } \\
\text { Altutunge }\end{array}$ & $\begin{array}{l}\text { House of } \\
\text { Abdouni }\end{array}$ & $\begin{array}{l}\text { House } \\
\text { of Ziada }\end{array}$ \\
\hline \multicolumn{6}{|l|}{ Elements of composition } \\
\hline Materials & A variety of materials are plaster, stone and marble. & $*$ & * & * & * \\
\hline Building system & $\begin{array}{l}\text { Basic system is a bearing walls system with structural } \\
\text { system in some parts such as Basement and Arcades }\end{array}$ & $*$ & $*$ & $*$ & $*$ \\
\hline \multicolumn{6}{|l|}{ Architectural treatments } \\
\hline \multicolumn{6}{|l|}{ The forms of arches and openings } \\
\hline The main entrance & Arc tapered & * & * & * & * \\
\hline Ewan & Arc tapered & * & * & * & * \\
\hline \multirow[t]{2}{*}{ The rooms entrance } & without arc (the high threshold is straight) & * & * & * & * \\
\hline & Arc Oblate (arc of Mosul) & $*$ & & & \\
\hline \multirow[t]{3}{*}{ Windows } & without arc & * & & & \\
\hline & Circle arc & * & & & \\
\hline & Arc Oblate (arc of Mosul) & $*$ & $*$ & $*$ & * \\
\hline \multirow[t]{3}{*}{ Galleries } & circle arc & * & & & \\
\hline & Arc tapered & * & * & * & \\
\hline & Without arc & * & & & \\
\hline \multicolumn{6}{|l|}{ Architecture treatments of openings } \\
\hline \multirow[t]{2}{*}{ The main entrance } & Framing of the stone with decorative treatments & $*$ & $*$ & & \\
\hline & Framing of the stone without decorative treatments & & & * & * \\
\hline \multirow[t]{2}{*}{ Ewan } & $\begin{array}{l}\text { Framing by more than one the framework of marble } \\
\text { with decorative and written treatments }\end{array}$ & * & $*$ & $*$ & \\
\hline & Without decorative treatments & & & & * \\
\hline \multirow[t]{2}{*}{ The rooms entrance } & Framing of marble without decoration & & & * & \\
\hline & Framing of marble with decoration & & $*$ & & $*$ \\
\hline \multirow[t]{2}{*}{ Windows } & Framing of marble without decoration & * & & * & \\
\hline & Framing of marble with decoration & & * & & \\
\hline \multirow[t]{2}{*}{ Arcades } & Framing of marble without decoration & & & * & \\
\hline & Framing of marble with decoration & * & * & & * \\
\hline \multicolumn{6}{|l|}{ Architecture treatments of walls } \\
\hline \multirow[t]{9}{*}{ Inner walls of the spaces } & Niches (niche in the walls) & * & * & * & * \\
\hline & Forms of niches in the corners or walls & $*$ & & & \\
\hline & $*$ Muqarnas & & & * & \\
\hline & A variety treatments of plaster & & & & \\
\hline & Decorative ledge & * & & & $*$ \\
\hline & Decorative tapes & $*$ & & & * \\
\hline & Frames from ornate plaster & * & * & * & * \\
\hline & Written plasterboard & * & & & * \\
\hline & $\begin{array}{l}\text { Cladding the walls with marble and } \\
\text { Elements of marble }\end{array}$ & & * & $*$ & * \\
\hline \multirow[t]{4}{*}{ Walls overlooking the courtyard } & $\begin{array}{l}\text { Cladding the walls with decorative marble or } \\
\text { non-decorative marble }\end{array}$ & $*$ & * & * & * \\
\hline & Niches (niche in the walls) & & * & $*$ & * \\
\hline & Cornices of marble and plaster & & & & \\
\hline & Stucco cladding & * & & * & * \\
\hline External walls & Stucco cladding & $*$ & * & * & * \\
\hline
\end{tabular}

*Muqarnas stalactite in scientific expression, but Muqarnas in all language when you are specialized in architecture- name of Arabic origin, forms of Asian origin-seljukide of Anatolia- XII century. A constructive way for transition from cube to dome

Either of the ways of collecting information to measure these variables was based on description of the buildings in the architecture literatures as well as the forms and charts and illustrations. The method to extract information from it is the process of analysis and observation to find the values of variables. The form number (A-1, B-1) describes this method, which represents a model for analysis of one house in the study sample.

As for the selection of samples, four samples that have been documented by the Office of Engineering
Construction have been selected. The reason is because it has maintained its architectural and structural components so far. Also, as one of the most important and the biggest houses in the city of Mosul, it has the characteristics that reflect the architecture in Mosul very well. Moreover, these houses were houses of powerful ruling class, which was taking into consideration the architectural aspects largely. In addition to that, these houses dated back to the preEngland colonial and before the change that took place in the schematic style of houses in Mosul (Aljumah, 
1989), as the building period of these houses return to the period between the mid-eighteenths to the second half of the nineteenth century.

These houses are: House of Amin Bik Al-Galilean in 1748, House of Al-Tutunge in 1815, House Abdouni the early eighteenth century AD and House Ziada in the second half of the nineteenth century AD.

The research methodology to select a goal and verification of a major hypothesis and secondary hypotheses will be:

- Define the concept of style and composition of an analytical system for measuring the characteristics of architecture style of the traditional houses, taking advantage of previous studies in this area

- The application of this analytical system on specific samples of the traditional houses in Mosul city

- Extract the characteristics of the architecture style of these houses through the application process

- Reach the general conclusions concerning the characteristics of the architecture style of Mosul houses to benefit in future designs

In the light of this methodology, the research contents have been sequenced:

The concept of style in architecture: The style has been defined in architecture in the light of the literature and ideas that it is language embodied sense physically; it has the fundamentals and rules of synthetic and formulation basis in the mind and requires them out into the world presence physical means or system to reflect the merits of building materials and construction techniques and other elements of the physical configuration (Kazim, 2000). On this basis the Style is a way or model. It is a medium to express spiritual values and civilization and humanity, a language that can be developed and adapt with the times (Kazim, 2000). Thus, the architecture style is the language containing the method or pattern to translate ideas into forms.

Whether the styles are products, the requirements of cultural, social, sensory, expressive or functional, it remains governed by the intellectual dimensions of absolute non-visual absolute and physical embodied visually (Kazim, 2000). The intellectual and cognitive dimension is style reflected in so-called model which represents a special case and limited features, the physical elements configuration contribute in embodying, the style generated by repeating this model (Kazim, 2000).
The change in the structure of intellectual and knowledge must be coupled with change in the models and the change in the composition of the physical components by different elements of the place and the emergence of new structural materials and new technology lead to emergence of a new model and the top of change resulting from the change in both intellectual and physical structure (Kazim, 2000).

Analytical system for measuring the characteristics of architecture style: Through what was covered on the Style concept showing that there are two levels of the style which are the intellectual, cognitive level and visual level. In other words, the concepts embody physically through the form. This research will focus on the level of physical configuration, without addressing the concepts of intellectual and knowledge that shaped it because the scope of this research is limited, but the concepts that shaped the Style of Mosul house can be taken up in complementary research in future.

The process of studying the characteristics of the architecture style of Mosul houses requires an analytical system with a basic vocabulary to diagnose these characteristics. In the architectural literature focus has been made on the physical composition of the architecture at multiple levels of the major architectural models that reflect the characteristics of the architecture style. The architectural literature indicated that the study of architectural models to purpose of extracting the physical characteristics of architecture style would require the following:

- Study the ingredients of physical composition for the period under study, which includes building materials and construction techniques and systems (Kazim, 2000; Akbar, 1981; Baker, 1996)

- Identify the basic building patterns and their basic components (Kazim, 2000; Akbar, 1981)

- Study the formal relationships of the architecture model and this can be manifested at several levels and as stated in many literature, especially by Frankel (Kazim, 2000); Akbar (1981) and Baker (1996)

The regulation of space: That dealt with devised basic characteristics of formal relations at the level of the schema through the schemes analysis of structural patterns which are the pattern of the basic organization of the schemes (Kazim, 2000; Baker, 1996), the movement system (Akbar, 1981; Baker, 1996), the gradient of space, levels of privacy (Akbar, 1981) and style of openness and its orientation (Akbar, 1981). 
The mass formation: that dealt with study the mass, its relations and Structure, Which is represent by study the general form and its relationship with space (Baker, 1996) and mass parts relations with each other (Kazim, 2000).

The treatments of architectural form: these deals with visual values of architecture, the detailed and decorative treatments that make the architectural style distinct (Kazim, 2000; Akbar, 1981). These are represented by openings of doors and windows and other openings and the manner and form of treatment as well as how to address a whole internal and external walls.

Application: The application process has been done for the four samples, included the analysis of forms, plans and illustrations, in addition to all cases of this description of the samples and the extraction of the values of variables for each sample. House of Amin Bik Al-Galilean put up as a model for the analysis and extraction of the values of variables. Form No. (A-1, B $-1)$.

The process of extraction the characteristic of architecture style of Mosul houses was taken through the extract of recurrent or similar characteristics in accordance with a specific format and in accordance with the vocabulary table of characteristics of architecture style, variables and values. Have been diagnosed the values of the basic components and relationships at the level of formal organization of space and composition mass, In addition to diagnosing the values of the repeated characteristic of Fine treatments and diagnostic the values of the development and stability of the building materials and prevailing structural techniques.

\section{Form No (A-1): House of Amin Bik Al-Galilean: Basic components:}

- There is main entrance leads to the general courtyard, through the intermediate space in the form of a right angle (Thanoon, 1983), plan (1). There are Canceled secondary entrances, one in the middle of the North Gallery and the other one in the old kitchen the through a tunnel connected with the house of Mohammad Sidique Galiean. There are two courtyards, one general for Reception, stables and other one is private for the population of House (Thanoon, 1983).

- House consists of the master suites composed of Ewan and rooms on either side, plan (3: a-3, b-3), Ewan open towards the courtyard and its ground higher than the level of ground courtyard, The level of its roof at the same level of the upper floor roof and It will be either at two-floor high or one-floor high according to its ground, Fig. 4: Section (1).

- The rooms are either individual rooms or connected with other spaces and its ceiling high can be either at one floor if there are rooms above or at two floors level, Fig. 4: Section (2).

- There are individual rooms and accessed to it by a Gallery or cantilever which separates the master suites and may be Rooms are either individual space or connected with other spaces and its ceiling high can be either at one floor or at two floors level

- There is an architectural elements building under the private courtyard in the western part which was a basement and access to it by stairs located in the south suite (Thanoon, 1983).

- There are Galleries in the house, as there were Gallery in the northern part under the northern suite the upper and had been cutting to several spaces (Thanoon, 1983) There is another Gallery in the South part as well as an new Gallery overlooking the General courtyard is Located on one side (Thanoon, 1983). In addition to the Galleries, there are cantilevers on the upper part and sides of the Ewan.

- There is a special part connected the private courtyard through the North Gallery which is kitchen part.

Formal relations:

Space organization:

- The pattern of the whole mass organization is a multi-center occupies the courtyard main focus in this configuration either the pattern of the detailed parts in house is a tripartite, Plan (1).

- The axes of movement Branched from the main courtyards to the spaces of house radially and link between these courtyards by axes movement indirectly through intermediate spaces and Arcades, Plan (1).

- That this organization is mostly reflecting a hierarchy of importance for the activities and the achievement of great depth and high level of privacy as the main spaces are not accessible only through the intermediate spaces, Fig. 2.

- The entrances of the main spaces open to intermediate space (Ewan, Arcade, Gallery) which opens toward the courtyard and some entrances of spaces

- either be inside these rooms or direct from the courtyard 
- For the windows, in general the main openness of spaces is toward the courtyard. This openness may be varied through intermediate space (Ewan, Gallery and Arcade), or the opening toward the courtyard directly, or have both together and opening to the outside will be limited to certain spaces that are open at the same time to inside house, Fig. 3: Plan (3: a-3, b-3; 4: a-4, b-4).

\section{Mass configuration:}

- The general shape is engineering irregular, consisting of several geometrical shapes grouped with each other; as the House took the form of site area allocated to it, Fig. 1.

- The mass structure surrounding courtyard, which represents the breath space in the house, but the degree of the surrounding, is not complete, as the mass structural surrounding the public courtyard in two sides and private courtyard in three sides

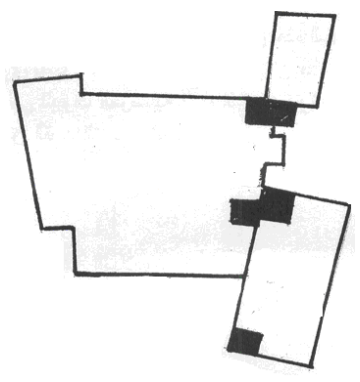

Fig. 1: Mass configuration

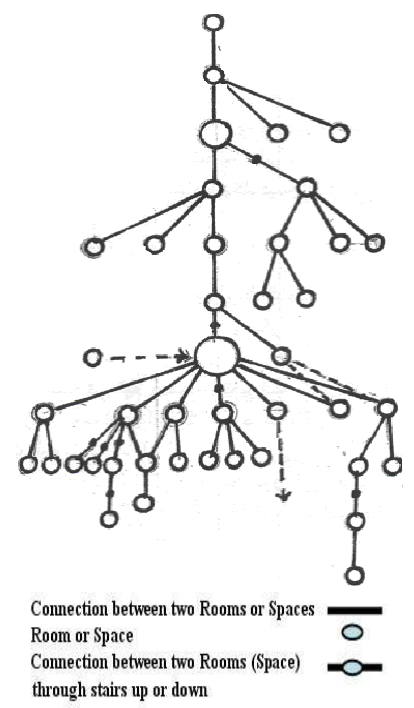

Fig. 2: Diagram of the space sequence
- The total mass, as evident from the general form is a multi-part, which is the public part, private part and services (kitchen) and these parts are linked through intermediate spaces represented by Gallery and secondary spaces to connect these parts

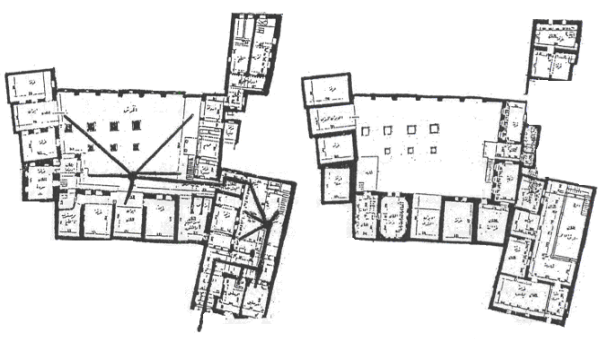

(a)

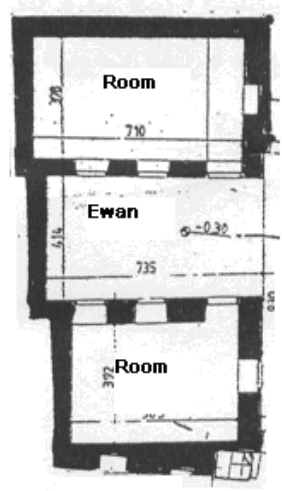

(c)

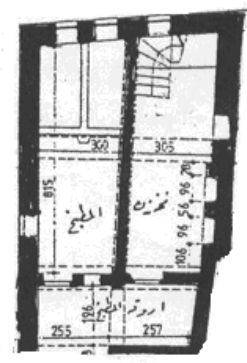

(e) (b)

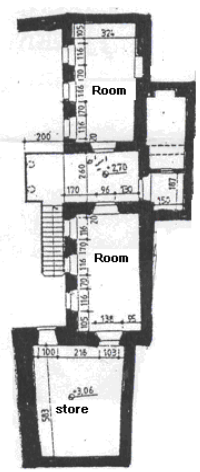

(d)

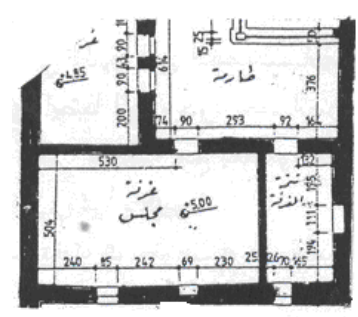

(g)

Fig. 3: (a): Plan 1: Ground floor; (b): Plan 2: First floor; (c): Plan 3: b-3; (d): Plan 3: a-3; (e): Plan 4: a-4; (f): Plan 4: b-4; (g): Plan 4: c-4 


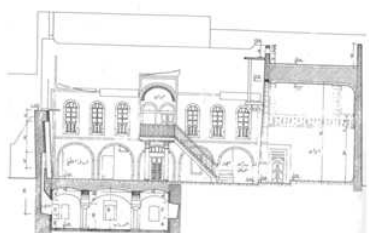

(a)

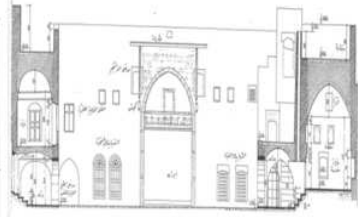

(b)
Fig. 4: (a): Section 1: In the inner courtyard, basement and Ewan and show the wall treatments; (b): Section 2: In Gallery, Arcade and Ewan and its treatments

- $\quad$ Each of these main parts consist of several suites with some individual rooms which are associated with each other through adjacent relationship or overlapping relationship and this relationship is often in the mass articulation of the house, Plan $(1,2)$

\section{Form No (B-1): House of Amin Bik Al-Galilean: Architectural configuration:}

Elements of composition: Materials which used in the house are variety represented by stucco, stone and marble those are basic Materials in building the structure and architectural treatments. The building system based on load bearing walls with the use of columns and arches (bridges) in the part of the basement, Fig. 4: Section (1 and 2).

\section{Fine architectural treatments:}

- The treatments of openings: The main entrance has arc tapered framed by ornate stone frames, Fig. 5: Photo no. (1).

- Ewan has Arc tapered framed by ornate stone frames, Section (2). The entrances of the rooms has arc Oblate (arc of Mosul) or without arch with the framing of marble, Section $(1,2)$.

- Windows have flat arch (Mosul Arch) or circular arc or without arch and be framed by the marble. Section (1 and 2). Galleries have different forms of arches, there are Galleries with circular arcs and paint brushes and without the arc (which is new) Section (1 and 2).

\section{Wall treatments:}

- Inner walls of the rooms and Ewan have a variety of treatments represented by Niches in the corners or walls in addition to a variety plaster treatments, are written and decorative panels, cornices and ribbons plaster decorated with and colorful, Fig. 5: Photo no. (2-4).

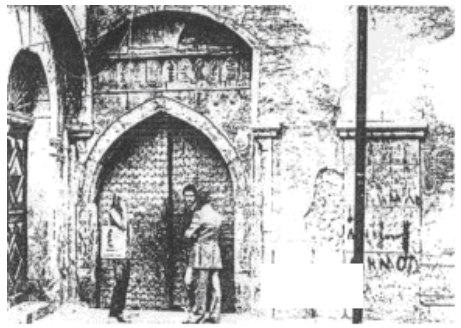

(a)

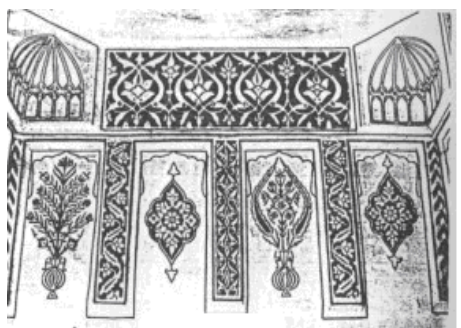

(b)

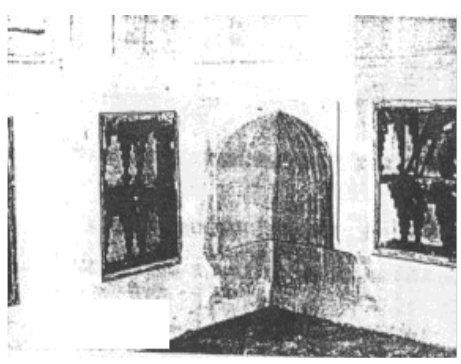

(c)

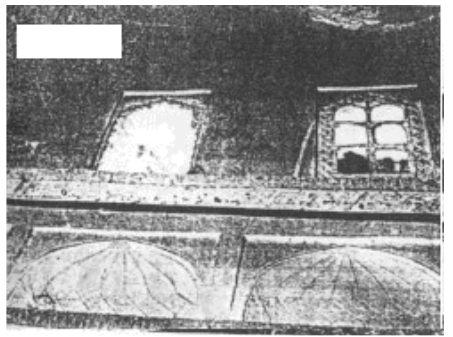

(d)

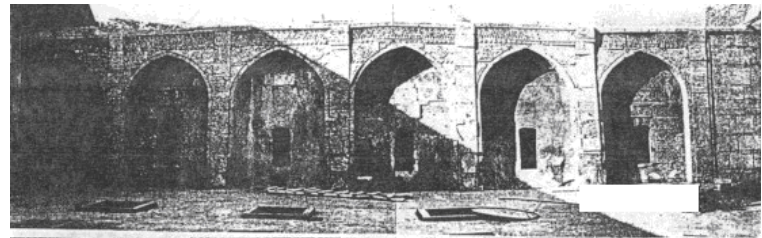

(e)

Fig. 5: (a): Photo no. 1: The main entrance; (b): Photo no. 2: Plaster treatments and cornices; (c): Photo no. 3: Niches in the corner; (d): Photo no. 4: Plaster treatments and cornices; (e): Photo no. 5: The western wall clad by marble and marble Arches 
- The walls overlooking the courtyard own different treatments, the western wall clad by marble and marble arches. The pillars adjacent to the wall filled with plant and engineering ornate marble, as well as for the south Gallery covered with ornate marble and the rest of the walls painted by stucco, Fig. 5: Photo no. (5) and Section (1 and 2).

- There are no fine architectural treatments in the exterior walls which are mostly adjacent to the walls of nearby houses, the walls overlooking the alley are painted by stucco, that do not have any architecture treatments except the main entrance and openings.

\section{RESULTS}

The results of the application: The values of variables of the system vocabulary analytical study of the samples were drawn after the analysis of these samples and then compare these values with each other for each variable of study samples to extract the common characteristics of architecture style.

The results of the application revealed a similarity in values of the most variables, which refer to common architectural features that illustrate architectural style of houses in Mosul. The results shown also that there are some architectural features that are not fixed in the model of house in Mosul because the values of these variables were different with each other which mean that these characteristics is not a constant presence and therefore has no role in determining the architectural style of these houses and can be seen from Table 1-3.

\section{DISCUSSION}

- There is a noticeable diversity in the main components of the houses in Mosul. There are two kinds of entrances namely the primary and secondary entrances. The rooms are either within main parts or conceived in separated parts. The basement will either be fully under the ground floor or its ceiling higher than the level of courtyard ground and under the building structure called "Alrhrh". Also, the galleries which are either parts of the building construction, or of light materials and which in general do not carry something above, are called cantilever

- Although the main components of houses in Mosul are various, different treatments are dedicated to these parts. The ceiling of Ewan can be up one floor or two floors as well as the Ewan also different from each other in the height of ground in the same house compare with the ground level of courtyard. The rooms are either single or a space communicates with another space and some of spaces communicate with other spaces through stairs called Attic. The Galleries are different in terms of surrounding to the courtyard with difference in surface treatments in each house (as in House of Amin Bik Al-Galilean)

- The idea of the house in Mosul is dependence of partition and the parts dominated on the whole at the level of regulation of space and the mass composition. Those parts of the houses (public, private, kitchen) are possibly independent from each other (actually this is what happened in the house of Altutunge at the present time, as its kitchen and public part were separated from the whole and became a contiguous houses)

- There is a difference between the pattern of regulation at the whole level and the regulation pattern of its parts. The overall composition is a multi-center; main part in the configuration is the courtyard, representing breather house and the construction parts of configuration overlooking toward it, in addition to being a distributor of the movement to these parts. The major parts in the configuration are the tripartite organization, regardless of the individual rooms (Independent rooms). These parts are possible to operate as an integrated system separated from the house as a whole so that some are used in the boarding upstairs

- The house of Mosul has a high Privacy, the access to the main focus of the house (the courtyard) is done through a series of median spaces and indirect entrance, in addition to the large Depths of the house space by the space sequence of the rooms. Also, the opening toward the main courtyard inside the house strengthens this Privacy. The opening is made through the intermediate spaces which are open toward the courtyard (through the Ewan and Galleries). The openness towards the outside is a little at the top floor and it is non-existent at the ground floor

- Mass composition is dominated by the irregular geometry and the mass composition control the space through the surrounding (especially the private courtyard). A large rise of the construction parts surrounding the courtyard, which makes the house having a distinct large mass

- There is an articulation in the mass composition which found between the major parts and the detailed, as the main parts connected with each other through intermediate spaces, the detailed parts connected with each other through the 
overlay and overlap in most cases and juxtaposition at other cases

- There is diversity in the materials that are used to build the houses for their multipurpose use. This is due to the fact that the material can be used in the process of building the main structure in addition to their use as fine treatments on the wall in the house. Plaster, stone and marble have been used as structural materials, as well as used as decoration materials in surfaces covering

- There is invaluable architectural treatment inside the house while the outside is characterized by its simplicity. The internal walls were treated through the decorative treatments, architectural elements (such as the niches) by the use of marble and plaster as well as in the framing of all kind of openings. In another side, exterior walls have the limited treatment through framing the opening by marble and stone. The main entrance has distinct rich decoration treatments and framing by stone

- The arc Ewan differed from the arc of windows and doors and sometimes with arc of Arcades. The arc of Ewan and the corridors were tapered and the windows and doors were flat arch (Arc Mosul). With a difference in some cases in the arches of the windows and doors and Arcades, using the forms of arches differ from the forms above the threshold as the circle and straight form (without arc)

\section{CONCLUSION}

Based on the findings, it can be concluded that the idea of the house in Mosul is dependence of partition and the parts dominated on the whole at the level of regulation of space and the mass composition which makes the house of Mosul has a high Privacy and has irregular geometry of Mass composition. And there is a difference between the pattern of regulation at the whole level and the regulation pattern of its parts which is due to the diversity in the main components of the houses. The diversity is not only in the main components of the houses, but also in the architectural treatments, in addition to the diversity in the materials that are used to build the houses for their multipurpose use especially inside the house while the outside is characterized by its simplicity.

\section{REFERENCES}

Akbar, J., 1981. Courtyard houses: A case study from Riyadh, Saudi Arabia, The Arab City, its character and Islamic heritage. Proceedings of a Symposium, AUDI, Medina, Saudi Arabia, pp: 162-176.
Aldeuge, S., 1982. Research in the Heritage of Mosul: Study in the Historical Sources and Plans for the Heritage of Mosul City. House Book for Printing and Publishing, Mosul, Iraq, pp: 70-137.

Janabi, K., 1982. Internal Structure of the Ancient City of Mosul-a Study in the Geography of Cities. House Book for Printing and Publishing, Mosul, Iraq, pp: 3-15.

Aljumah, A., 1982. Characteristics and traditional designs in the Mosul city. J. Mesopotamia Literat., 16: 8 .

Aljumah, A., 1988a. Authenticity of the economic system in the Mosul city and its buildings through the Arab Islamic centuries. Centre revive of Arab Scientific Heritage, University of Baghdad, Baghdad, Iraq, pp: 26.

Aljumah, A., 1988b. Environmental treatments of heritage housing designs in Mosul. Centre revive of Arab Scientific Heritage, University of Baghdad, Baghdad, Iraq, pp: 4.

Aljumah, A., 1989. Entrance of (Panjshir) palms Shrine Imam Ali in Mosul-an investigative study. J. Mesopotamia Literat., 19: 97.

Aljumah, A., 1992. The Contemporary Architecture, Cultural Encyclopedia of Mosul. House Book for Printing and Publishing, Mosul, Iraq, pp: 278.

Baker, G.H., 1996. Design Strategies in Architecture: An Approach to the Analysis of Form. 2nd Edn., E \& FN Spon, Van Nostrand Reinhold, New York, London, pp: 26-34.

Kazim, J.A., 2000. Dialectical communication in Iraqi architecture-Inductive Study to continuity of building models of Mesopotamia in the history of Iraqi architecture. Unpublished Doctoral Thesis, The Architectural Section, Faculty of Engineering, University of Baghdad, Baghdad, Iraq, pp: 63-79.

Sangaree, H.A., 1990. Compare the efficiency of the functionality and the economic rationalization of the spaces of the residential unit in the private and socialist. Unpublished Master Thesis, Department of Architecture, University of Technology, Baghdad, Iraq, pp: 8-12.

Thanoon, Y., 1983. Residential buildings in the city of Mosul-models of general documentation, the first part. The Office of Construction Engineering, Mosul, Iraq, pp: 4-101. 